\title{
A CATARSE NA COMÉDIA
}

\author{
ADRIANE DA SILVA DUARTE* \\ Faculdade de Filosofia, Letras e Ciências Humanas \\ Universidade de São Paulo
}

\begin{abstract}
RESUMO: A partir da revisão das várias teorias da catarse cômica, esse artigo busca discutir as emoções envolvidas nesse processo tendo em vista a comédia aristofânica. Ao final, tendo em vista a teoria aristotélica das paixões, aponta-se a indignação e a confiança como as emoções que possibilitam a eclosão do riso, o veículo da catarse.
\end{abstract}

PALAVRAS-CHAVE: catarse; Aristóteles; Poética; Retórica; comédia grega antiga.

Qualquer abordagem da catarse deve iniciar-se com a advertência das suas limitações. Faço minhas as palavras de Campbell (2001: 233) em um artigo recente que promete uma nova luz sobre um assunto tão polêmico: "Qualquer interpretação da catarse é inevitavelmente especulativa e sempre suspeita devido à controvérsia que cerca seu significado".

Apesar das dificuldades inerentes à questão, muitos se debruçaram sobre ela. Eudoro de Souza (1986: 98-99), no estudo introdutório à sua tradução da Poética, nota que a grande quantidade de estudos dedicados à catarse "traduz não somente o interesse, como também o desespero, perante o indecifrável enigma daquelas palavras em que o Filósofo mais não diz senão que a tragédia, suscitando terror e piedade, tem por efeito a purificação desses sentimentos". Vale lembrar que, no corpus aristotélico, o termo catarse aparece uma única vez na Poética (1449 b 27) e outra na Política (VIII 7), sem que qualquer definição lhe seja aposta.

Embora os mistérios da catarse, ou seja, como ela opera no espectador, não estejam no cerne desse artigo, dedicado mais à definição das emoções cômicas

* Professora de Língua e Literatura Grega atualmente na graduação (PPG de Letras Clássicas). Pesquisadora do CNPq (PQ). 
envolvidas nesse processo, considero imprescindível apresentar um breve apanhado das interpretações preponderantes. Para isso, valho-me novamente de Campbell (2001: 226-227), devido ao seu poder de síntese e clareza ${ }^{1}$ :

A interpretação da catarse pode ser dividida, mais ou menos, entre duas escolas. K $\alpha \theta \alpha p o ́ s$, sem qualquer raiz indo-européia evidente, abrange um espectro de significados que vai do fisicamente limpo ao abstratamente puro. $\mathrm{O}$ adjetivo $\kappa \alpha \theta \alpha \rho o ́ \varsigma$ produziu o verbo $\kappa \alpha \theta \alpha \dot{t}$

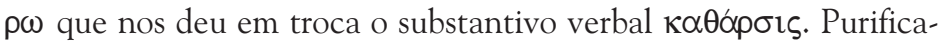
ção religiosa e purgação médica, com seus significados técnicos, sugerem as duas principais escolas de interpretação. O sentido de "purificação" na catarse foi redefinido certamente desde Lessing para significar "educação" - especialmente a educação das emoções. [...] A outra interpretação da catarse deriva da idéia de "purgação", que foi identificada por J. Bernays, que na última metade do século passado [i.é, séc. XIX] estabeleceu a questão a partir de uma referência cruzada na Política. Catarse, ele argumentou, significava a eliminação da emoção excessiva e uma restauração temporária do equilíbrio emocional na audiência. ${ }^{2}$

Richard Janko (1984: 142 e 2001: 65) se refere às duas correntes como "purgacionista" e "homeopática", na medida em que defendam a supressão, ainda que momentânea das emoções trágicas, ou a sua depuração, visando à moderação na vida real. A elas, veio a se somar recentemente uma visão "alopata" da catarse, que defende a purificação, através da piedade e do terror, dos sentimentos contrários a estes, como a impiedade e o excesso de confiança. ${ }^{3}$ Como se vê, a catarse aristotélica produziu toda uma farmacopéia. Com isso torna-se claro que não há uma teoria aristotélica da catarse e sim teorias da catarse aristotélica.

Um ponto consensual entre as diversas vertentes é a crença de que a catarse está no núcleo da resposta aristotélica à teoria da mimese de Platão e da sua conseqüente condenação da poesia expressas no livro X da República ${ }^{4}$. Se, para

1 Também são úteis as sínteses de Golden (1976), Janko (1984: 139-150) e Halliwell (1997: 89-92).

2 Cf. Bernays (1979:154-165).

3 Cf. E. S. Belfiore, a partir de Nehamas (1994: 273, n. 27).

4 Nem mesmo nesse ponto há unanimidade. Embora concorde que esse pressuposto é aceito quase universalmente, Nehamas (1994: 275-277) discorda que o conceito de 
o fundador da Academia, as artes miméticas, e muito especialmente a tragédia, são nocivas por apelar diretamente à parte irracional da alma, suscitando emoções que, no trato social, deveriam ser contidas, para o Estagirita, esse mesmo processo teria por resultado, senão a eliminação de determinados sentimentos, a sua educação. Dessa maneira, a arte, ao garantir o equilíbrio dos cidadãos, agiria antes em benefício da sociedade do que em seu prejuízo.

Se a situação já é nebulosa no que concerne à tragédia, fica ainda pior quando a comédia está em foco. De início, pode-se questionar a pertinência de usar o termo em relação à comédia já que nenhuma passagem da Poética traz essa associação. Vale lembrar a definição que Aristóteles dá ao gênero (1449 a 32):

A comédia é, como dissemos, imitação de homens inferiores

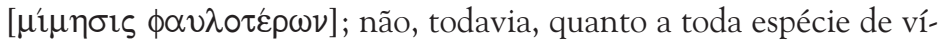

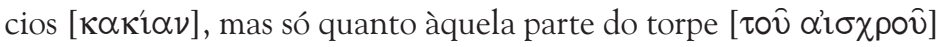

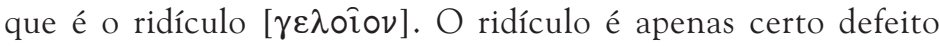
[ó $\mu \alpha ́ \alpha \tau \eta \mu \alpha]$, torpeza anódina e inocente [indolor e não destrutiva,

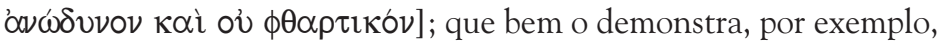
a máscara cômica, que, sendo feia e disforme, não tem [expressão de] dor. ${ }^{5}$

Como se vê, o que caracteriza a comédia para o Filósofo é 1) a mimese de homens

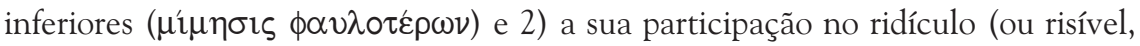
$\gamma \varepsilon \lambda \circ i ̂ v)$. Ao contrário do que ocorre na definição da tragédia (1449 b 24), nada se diz sobre a catarse ou sobre as emoções que estariam envolvidas nesse processo.

Essa ausência, significativa ao meu ver, não desencorajou os que preferiram justificá-la alegando que a aplicação da teoria da catarse à comédia integraria o segundo livro da Poética que, infelizmente, teria se perdido. ${ }^{6} \mathrm{O}$ emprego do condi-

catarse constitua a resposta de Aristóteles às críticas de Platão à poesia e propõe uma interpretação do termo que independe desse contexto.

5 Todas as citações da Poética são da tradução de Eudoro de Souza, cf. Aristóteles (1987).

6 A título de exemplo das especulações às que a questão dá margem, cf. Janko (2001: 52): "A Poética de Aristóteles perdeu o seu segundo livro, que tratava da comédia e da catarse, em algum momento da Antigüidade tardia. [...] A verdade pode ser mais prosaica [do que supõe Umberto Eco em O Nome da Rosa]: a Poética foi aposta como último item na coleção das obras lógicas de Aristóteles, se o segundo livro chegou mesmo a ser transferido do rolo para o codex, o que pode nunca ter acontecido, ele ocuparia a parte final do volume estando mais sujeita a cair caso a costura se afrouxasse". 
cional na frase anterior evidencia o alto grau de especulação que a questão suscita. Que Aristóteles tenha dotado a Poética de um segundo livro, é algo que está longe de ser consensual entre os estudiosos e cuja solução parece estar bem distante tendo em vista as fontes de que (não) dispomos. Se, por um lado, não se conhece o testemunho de qualquer leitor desse famosíssimo livro, outro silêncio eloqüente ao meu ver, por outro temos a passagem da Política (VIII 7, 1341 b 32 ss) que remete à Poética para elucidação do termo e o final sugestivo, mas estropiado, de um dos três manuscritos que nos chegaram desse texto (1462 b 16) ${ }^{7}$ :

Falamos, pois, da tragédia e da epopéia, delas mesmas e das suas espécies e partes, número e diferenças dessas partes, das causas pelas quais resulta boa ou má a poesia, das críticas e respectivas soluções. Dos jambos e da comédia... [itálicos meus].

Estimulados por essa vaga promessa (?), vários estudiosos se lançaram em busca de fontes que permitissem reconstituir o conteúdo do livro perdido. Merece destaque o esforço de Janko (1984), que viu num tratado do séc. X d.C., o Tractatus Coislinianus, uma fonte privilegiada para tal tarefa. A tese de Janko (2001: 52) é a de que o Tratado contenha um resumo, em formato esquemático, da Poética II, constituindo, portanto, um testemunho direto da teoria aristotélica sobre a comédia. Ele mesmo reconhece que os problemas de corrupção textual e as inconsistências do Tratado são obstáculos para a aceitação de seu ponto de vista, hoje amplamente questionado. ${ }^{8}$ Apesar disso, toda a discussão da catarse cômica tem aqui o seu início, uma vez que, no documento, comédia e catarse aparecem associados na própria definição do gênero:

IV. A comédia é imitação de uma ação risível e de grandeza imperfeita, completa, em linguagem ornamentada, separada em várias es-

7 Somente o MS Riccardianus 46 registra esse início de frase.

8 Como exemplo das reações adversas, veja-se a observação feita por M. Heath (1988: 344): "Meu objetivo nesse artigo é recosinderar vários aspectos da reflexão de Aristóteles sobre a comédia à luz do corpus aristotélico. Eu não devo dizer nada sobre o Tractatus Coislinianus, um pequeno documento obscuro e contencioso, que (a despeito dos esforços enérgicos de Richard Janko para restaurar seu crédito) permanece um ponto de partida inadequado para a discussão." Sobre Aristotle on Comedy de Janko, ele diz (n. 1) ser "um livro amplamente admirado e desacreditado", arrolando seus críticos. Cf. também o balanço feito pelo próprio Janko (2001: 52-52) da recepção de seu livro. 
pécies [de ornamento] em cada uma das suas partes, [a imitação se dá] com atores e não pela narrativa; pelo prazer e pelo riso efetuando a catarse de tais afecções. E tem como mãe o riso. ${ }^{9}$

Antes de entrar propriamente na discussão do significado desse texto para concepção da catarse cômica, gostaria de apontar para o paralelismo, quase que absoluto, que há entre essa passagem e a definição da tragédia na Poética (1449 b 24). Vou reproduzir os dois textos em grego para ressaltar a simetria que guardam entre si:

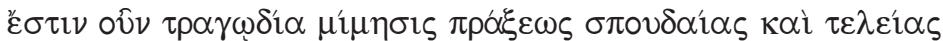

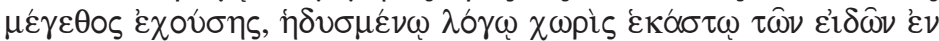

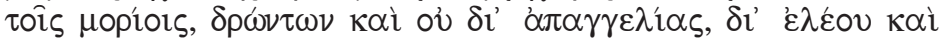

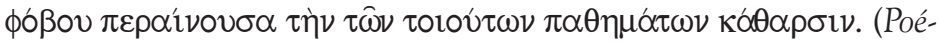
tica $)^{10}$

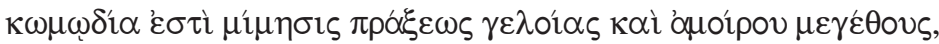

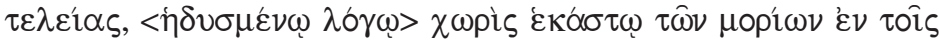

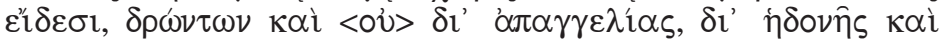

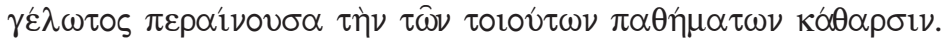

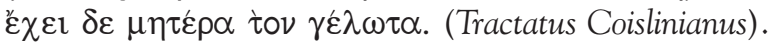

O texto do Tratado sofreu diversas correções - o aparato crítico é considerável -, e dois acréscimos, indicados pelos parênteses oblíquos, cuja base declarada foi a definição da tragédia na Poética. ${ }^{11}$ Tal semelhança, ao invés de corroborar a autenticidade do texto do Tratado, lança ainda mais suspeitas sobre ele, sugerindo que seu autor se valeu de um procedimento grosseiro, ou seja, o de produzir uma definição para a comédia calcada na que a Poética apresenta para a tragédia, pois,

9 Janko (1984) editou e traduziu o Tratado para o inglês, em português há uma tradução de Possebon (2000), inserida entre os anexos que fazem parte de sua dissertação de mestrado. A tradução aqui apresentada é, no entanto, minha.

10 Cf. a tradução da passagem por Eudoro de Souza (Aristóteles, 1986:110): "É, pois, a tragédia imitação de uma acção de caráter elevado, completa e de certa extensão, em linguagem ornamentada e com várias espécies de ornamentos distribuídas pelas diversas partes [do drama], [imitação que se efectua] não por narrativa, mas mediante actores, e que, suscitando o terror e a piedade, tem por efeito a purificação dessas emoções".

11 Para uma avaliação da passagem, cf. Janko (1984: 151-153). Em outro texto (2001: 65), o mesmo autor declara que a "definição foi emendada para fazer sentido (e para fazê-la mais aristotélica) por vários estudiosos, eu mesmo por último e por final”. 
como nota Janko (1984: 151), "é de se presumir que as definições dos termos dada na Poética 6 não seriam repetidas na Poética II".

Mas os problemas não param por aí. A análise do conteúdo mostra que o paralelismo é em parte aparente, ao menos no que concerne à catarse. Embora o Tratado atribua a catarse cômica à ação de dois elementos, o prazer e o riso

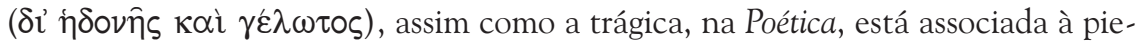

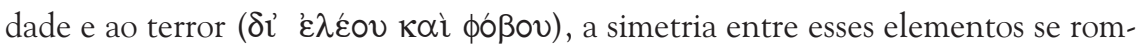
pe. Nos dois textos, piedade, terror, prazer e riso são definidos como emoções $(\pi \alpha \theta \eta \mu \alpha ́ \alpha \omega \nu)$, mas não me parece evidente que eles de fato o sejam e nem que Aristóteles os colocasse num mesmo patamar.

Esse desequilíbrio foi logo notado pelos críticos do pretenso aristotelismo do Tratado. A principal objeção diz respeito à pertinência de arrolar o prazer

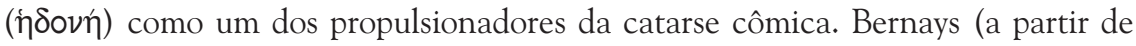
Janko, 1984: 157) nota que, sendo o riso subordinado ao prazer, conforme o próprio Aristóteles estabelece na Retórica (I 111371 b 35), os termos não deveriam aparecer coordenados. Na mesma obra, o Filósofo apresenta uma definição de emoção da qual fazem parte o prazer e a dor. Diz ele (II 11378 a 19):

As paixões ( $\tau \dot{\alpha} \pi \alpha ́ \theta \eta \eta)$ são todos aqueles sentimentos que, causando mudança nas pessoas, fazem variar seus julgamentos, e são seguidos

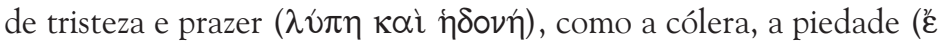
$\lambda \varepsilon \circ \varsigma$ ), o temor ( $\phi o ́ \beta \circ \varsigma)$ e todas as outras paixões análogas, assim como os seus contrários. ${ }^{12}$

Se a certas emoções segue-se o prazer, isso significa que Aristóteles não o considerava um páthos como é o caso da piedade e do terror, ali denominados.

Além disso, na Poética, Aristóteles reconhece a existência de um prazer próprio à tragédia (XIV, 1453 b 8):

Quanto aos que procuram sugerir pelo espetáculo, não o tremendo, mas o monstruoso, esses nada produzem de trágico; porque da tra-

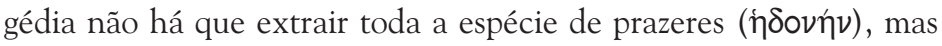

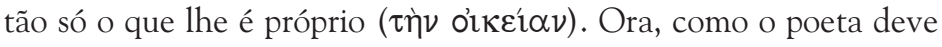

12 As traduções do segundo livro da Retórica são de Isis Borges B. da Fonseca (Cf. Aristóteles, 2000). 


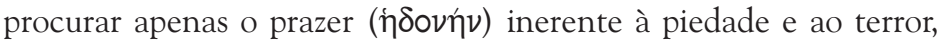
provocados pela imitação, bem se vê que é da mesma composição dos factos que se integram tais emoções.

Esse prazer trágico está, como se vê no texto, associado ao sentimento de piedade e ao terror e, portanto, é efeito da catarse e não seu objeto - ao contrário, já que as emoções trágicas são por natureza dolorosas. $\mathrm{O}$ mesmo raciocínio deve valer para a comédia, já que Aristóteles se refere explicitamente a "um prazer que lhe é próprio" por oposição ao trágico (XIII, 1453 a 10) ${ }^{13}$ Ora, tal prazer deve ser inerente a certas emoções e não a si próprio.

Diante da inadequação do termo, Golden (1987: 169) vai buscar no próprio Aristóteles, no segundo livro da Retórica, que trata das emoções, o equivalente cômico para o par trágico terror e piedade. A solução me parece especialmente engenhosa porque a obra nos põe em contato direto com a visão aristotélica das paixões e porque o Filósofo mesmo indica para cada uma das emoções analisadas a que lhe é contrária. ${ }^{14} \mathrm{~A}$ idéia se sustenta na observação de que Aristóteles vê a comédia como a antítese da tragédia. Da definição do gênero na Poética (1449 a 32, citada acima), depreende-se que a comédia imita "homens inferiores" ( $\mu$ '́ $\mu \eta \sigma 1 \varsigma$ $\phi \alpha v \lambda \circ \tau \varepsilon \varepsilon \omega v)$, enquanto a tragédia é imitação de uma "ação de caráter elevado"

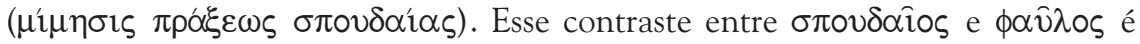
recorrente na Poética (1448 a 1-2; 1448 b 24-27) e índice da polarização com que Aristóteles trata os gêneros dramáticos. Heath (1989: 352) acrescenta a isso o fato

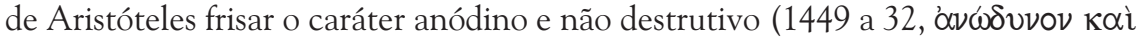
ou $\phi \theta \alpha \rho \tau \imath \kappa o ́ v)$ da comédia por oposição à tragédia, cujo enredo contempla a ca-

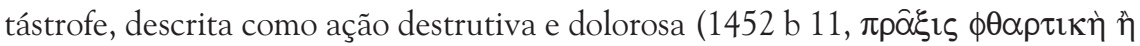
ódvvnpó). Com tudo isso em vista, Golden (1987: 170) conclui:

Já que tragédia e comédia são postas por Aristóteles em oposição polar no que concerne ao tipo de ação e caráter que representam, a

13 "Cabe o segundo lugar, não obstante alguns lhe atribuírem o primeiro, à tragédia de dupla intriga, como a Odisséia, que oferece opostas soluções para os bons e para os maus. [...] Mas o prazer que resulta desse gênero de composições é muito mais próprio da comédia, porque nela os que são na lenda inimicíssimos, como Orestes e Egisto, se tornam por fim amigos e nenhum deles é morto pelo outro".

14 Contra a opinião de que o tratamento dado por Aristóteles às emoções na Retórica é superficial e eivado de lugares-comuns por estar subordinado a uma finalidade prática, cf. Fortenbaugh (1979) e Nehamas (1994: 262). 
identificação de $\nu \varepsilon \mu \varepsilon \sigma \alpha \hat{\nu} \nu$ como antônimo de "̌̉ $\lambda \varepsilon \circ \varsigma$ fornece uma pista sugestiva para o desvelamento de um aspecto importante da teoria aristotélica da comédia.

Na Retórica II, Aristóteles aponta $\nu \varepsilon \mu \varepsilon \sigma \alpha \hat{\nu}$, indignação, como a emoção contrária

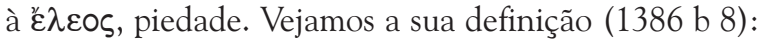

Opõe-se à compaixão ( $\tau \hat{\omega}$ દ่ $\lambda \varepsilon \varepsilon \varepsilon \hat{\imath} \nu)$ sobretudo o que se chama indignação $(\nu \varepsilon \mu \varepsilon \sigma \alpha \hat{\nu})$; com efeito, ao sentimento de pesar pelos infortúnios imerecidos contrapõe-se, de certa maneira, e procede do mesmo caráter, o pesar ( $\tau \grave{\partial} \lambda \nu \pi \varepsilon \hat{\imath} \sigma \theta \alpha \imath$ ) pelos sucessos imerecidos. Ambos os sentimentos ( $\tau \dot{\alpha} \pi \dot{\alpha} \theta \eta \eta)$ decorrem de um caráter honesto. Devese sentir aflição e compaixão pelos que são infelizes sem o merecer, e indignação pelos imerecidamente felizes.

Que a indignação esteja profundamente implicada na comédia, testemunham as comédias de Aristófanes, pois é justamente esse sentimento que move o herói cômico. De um Diceópolis, em Acarnenses, insatisfeito com as regalias de embaixadores e políticos em contraposição aos sofrimentos causados pela guerra à população, a um Cremilo, em Pluto, inconformado com o enriquecimento imerecido de pilantras de vários tipos enquanto os honestos são relegados à penúria, todos os heróis aristofânicos se revoltam contra uma situação que consideram injusta. Portanto, é natural pensar que essa indignação comunique-se de alguma forma à platéia tornando-se imprescindível para que haja aquela explosão de riso decorrente do castigo dos desonestos. Como observa Aristóteles (1386 b 24):

[...] quem sente pesar pelos que imerecidamente são infelizes se alegrará, ou pelo menos não experimentará pesar pelos que merecidamente são infelizes [...].

Assim, aquele "bem-feito" que acompanha a gargalhada diante de um Paflagônio condenado a vender salsichas nos portões da cidade, em Cavaleiros, ou do Pensatório em chamas n' As nuvens, nasce antes de mais nada do sentimento de indignação. É justamente esse riso zombeteiro diante de um adversário batido a forma mais freqüente de riso nas comédias aristofânicas, segundo o levantamento feito por Sommerstein (2000: 68).

Nesse ponto, Golden dá-se por satisfeito e abandona a questão. Para ele, assim como para a maioria dos comentadores, é mais fácil engolir o riso como um 
dos elementos envolvidos na catarse cômica do que o prazer..$^{15}$ Isso acontece porque, na definição de comédia na Poética (1449 a 32, citada acima), Aristóteles aponta o risível ou o ridículo ( $\gamma \varepsilon \lambda \circ i ̂ \nu)$ como sua essência.

Com certeza o riso diz respeito à comédia e pode-se imaginar com facilidade o papel que ele desempenharia na catarse cômica. Assim poucos discordariam do autor do Tractatus Coislinianus quando afirma que a comédia "tem como mãe o riso" ( $\tau \grave{o} \nu \gamma \varepsilon \dot{\lambda} \lambda \tau \tau \alpha$, citado acima). No entanto, o que não é claro para mim, é a função desse elemento no processo catártico.

Um dos maiores problemas implicados no exame da questão é de natureza terminológica. Como bem observou Scruton (1982: 198):

Riso é um termo enganoso. Nós o empregamos para indicar sons emitidos por alguém que está sob efeito de cócegas, certas expressões de escárnio ou espanto, o 'riso oco' que acompanha a percepção da ruína de alguém. Em seu sentido mais amplo (no qual denota um som produzido pela boca de um ser sensível) nós usamos o mesmo termo para as hienas.

A essas acepções, valeria ainda acrescentar a definição de riso enquanto um fenômeno físico que envolve a contração muscular de músculos faciais, como, por exemplo, o ricto involuntário dos mortos ou de certos doentes. Esse quadro é bem verdadeiro no que respeita a Grécia Antiga. Embora o vocabulário do riso e do rir comporte alguma variedade, os gregos, sobretudo os do período clássico, elegeram $\gamma \dot{\varepsilon} \lambda \omega \varsigma, \gamma \varepsilon \lambda \dot{\alpha} \omega$ e seus derivados para dar conta dos diversos espectros que o fenômeno comporta. ${ }^{16}$

Primeiramente é preciso estabelecer se o riso é uma emoção, um páthos, para os gregos e muito particularmente para Aristóteles. Não me parece que esse seja o caso, já que considero o riso antes de mais nada como veículo para a expressão de uma emoção ou de uma sensação (física, no caso das cócegas) e, nesse

15 Golden (1987: 172) propõe que a indignação seja o equivalente cômico do terror e piedade trágicos, tendo em vista a interrelação existente entre eles e o fato de Aristóteles notar que o sentimento de indignação por alguém que é feliz sem merecer se mistura freqüentemente ao de terror, caso esse alguém esteja em condição de nos ameaçar.

16 Cf. Eire (2000: 14): "Portanto, os gregos possuem três palavras, e conseqüentemente três noções, para enunciar de modo específico a ação de 'rir', que se exprime de modo geral pelo verbo $\gamma \varepsilon \lambda \hat{\alpha} \nu$.” Ver também Sommerstein (2000: 65-66). 
sentido, um fenômeno assemelhado ao choro. Fortenbaugh (2000: 333), num estudo sobre o tratamento das emoções em Aristóteles, dá-nos uma pista para o tratamento da questão ao observar que na Retórica, embora o Filósofo reconheça a importância do riso para o orador,

[...] ele não lhe dedica em parte alguma um tratamento detalhado comparável àquele da cólera, do medo ou de outras emoções que ele agrupa sob a etiqueta de páthos.

Mais adiante, Fortenbaugh esclarece que o riso constitui uma resposta emocional ao que é prazeroso, resposta essa que se apresenta em múltiplas formas. $\mathrm{O}$ fato de ser deflagrado por uma emoção não implica a sua irracionalidade, pois como o mesmo autor se esforçou por demonstrar, o processo cognitivo é uma parte essencial da resposta emocional (1979: 134). Embora suponha que o riso possa ter recebido da parte de Aristóteles um tratamento semelhante ao das emoções na Retórica, Fortenbaugh (2000: 342) aponta, no decorrer da sua análise das várias espécies de riso, as emoções que, ao seu ver, estariam implicadas nesse processo, a saber, a inveja ou a cólera. Vale lembrar que ele pensa o fenômeno em sua multiplicidade e não na sua aplicação à comédia antiga.

Feitas essas observações, proponho retomar a discussão no ponto em que Golden a deixou. Nunca entendi porque ele não estendeu ao terror ( $\phi o ́ ß ం \varsigma)$ o

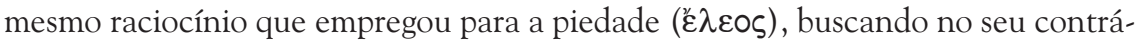
rio o outro elemento que ao lado da indignação ( $\nu \varepsilon \mu \varepsilon \sigma \alpha \hat{\nu})$ comporia o par das emoções cômicas. Examinemos o que diz Aristóteles na Retórica (1383 a 19):

O que inspira a confiança $(\theta \alpha p \rho \alpha \lambda \varepsilon \dot{\varepsilon} \alpha)$ é o distanciamento do temível e a proximidade dos meios de salvação. E igualmente se há meios de reparação e de proteção numerosos ou importantes, ou as duas coisas ao mesmo tempo; se não sofremos nem cometemos injustiça; se absolutamente não temos antagonistas, ou eles não têm poder, ou se, tendo poder, são nossos amigos, ou nos fizeram um favor ou o receberam de nós. Ou então se os que têm os mesmos interesses que nós são mais numerosos ou mais fortes, ou as duas coisas ao mesmo tempo.

Em vista dessa definição, pode-se afirmar que é o sentimento de superioridade e de imunidade que sustenta a sensação de confiança. É justamente esse estado que é normalmente apontado como essencial para que se produza o riso. Como nota Fortenbaugh (2000: 345), se extrairmos plenamente as conseqüências das obser- 
vações da Poética sobre o objeto da imitação cômica, os homens inferiores ( $\phi \alpha \nu \lambda \circ \tau \varepsilon \rho \omega \nu)$, concluiremos que:

[...] o julgamento que faz rir é uma comparação de duas pessoas: uma que é considerada inferior e outra que ri. A última se imagina superior e seu riso pode ser mais ou menos uma expressão de satisfação devida a sua própria superioridade.

Também o herói cômico, ao zombar de um adversário batido, faz isso imbuído do sentimento de confiança. Esse inimigo, destituído de seu poder e autoridade, não representa mais nenhum perigo para o herói ou para os seus. Este é bem o caso de Lâmaco ou do Paflagônio, ao final de Acarnenses e de Cavaleiros, respectivamente.

A confiança também está na base de outra espécie de riso detectado na comédia aristofânica. Sommerstein (2000: 74-75) aponta, ao lado do riso zombeteiro, a presença do riso compartilhado em decorrência de um prazer. Ele relaciona quatro fontes deste riso, a saber: os prazeres da festa; os prazeres do amor; o fato de ter escapado a um perigo ou dor; uma reconciliação ou reunião após uma separação. No que concerne aos dois últimos motivos, especialmente, me parece que o sentimento de confiança, tal qual o descreve Aristóteles, esteja implicado. Portanto, são igualmente numerosos na comédia de Aristófanes exemplos de situações em que o riso brota desse estado de alma, como mostram os finais felizes, em que todos os obstáculos ao bem-estar do herói foram superados e não há mais nada a temer.

Por fim, não posso deixar de notar a relação de reciprocidade que o par indignação e confiança mantém entre si, pois só se pode expressar livremente a indignação quando se está confiante de que se está a salvo da reação dos que são alvos dela.

Numa conhecida passagem das Viagens de Gulliver, Swift imagina o encontro de Aristóteles com todos os comentadores de sua obra desde a Antigüidade. $O$ grupo era tão numeroso - e seria ainda consideravelmente maior, se fossem incorporados os que se dedicaram a essa tarefa nos últimos trezentos anos -, que não cabia num salão, espalhando-se pelas demais salas e pelo pátio do palácio. Ao ser apresentado a dois dos mais ilustres membros do clube, Escoto e Ramus, Aristóteles "perdeu a paciência [...] e perguntou-lhes se o resto da tribo era constituído de asnos tão grandes como eles". ${ }^{17}$

17 Cf. Swift, J. Gulliver's Travels. Harmondsworth/Middlesex: Penguin Books, 1982, p. 242 (parte 3, cap. 8). 
Conto essa história somente para frisar que sei os riscos que corro e consciente deles não pretendo que a minha investigação seja uma reconstrução do pensamento de Aristóteles sobre o tema. Assim se justifica plenamente o paradoxo que a norteou, ao levar ao extremo o procedimento de clonagem da definição de tragédia na Poética, antes criticado em relação ao autor do Tractatus Coislinianus. Apresento antes um exercício que parte e tem por base elementos da reflexão aristotélica sobre os gêneros dramáticos e sobre as emoções. Após percorrer esse caminho, poder apontar a indignação e a confiança como as emoções cômicas que possibilitariam a eclosão do riso, o veículo da catarse, significa ampliar as possibilidades de compreensão da comédia. É uma pequena contribuição para um debate que estará sempre em aberto.

\section{REFERÊNCIAS BibLIOGRÁFICAS}

ARISTÓTELES. Poética. Tradução, introdução, comentário e apêndices de Eudoro de Souza. Lisboa: Imprensa Nacional/Casa da Moeda, 1986.

. Retórica das paixões. Introdução, tradução e notas de Isis Borges B. da Fonseca. São Paulo: Martins Fontes, 2000.

ARISTOTLE. Poetics. introduction, commentary and appendixes by D.W. Lucas. Oxfordd: Claredon Press, 1972.

BERNAYS, J. Aristotle on the effect of tragedy. In Barnes, J.; Schoefield, M.; Sorabji, R. (ed.) Articles on Aristotle. 4. Psychology and aesthetics. London: Duckworth, 1979, p. 154-165.

CAMPBELL, J. S. Painless pleasure: catharsis in the Poetics. Les Études Classiques, 69, p. 225-236, 2001.

EIRE, A. L. À propos des mots pour exprimer l'idée de 'rire' en grec ancien. In Desclos, M-L. (org.). Le rire des Grecs. Anthropologie du rire en Grèce ancienne. Grenoble: Editions Jérôme Millon, 2000, p. 13-43.

FORTENBAUGH, W. W. Une analyse du rire chez Aristote et Théophraste. In Desclos, M-L. (org.). Le rire des Grecs. Anthropologie du rire en Grèce ancienne. Grenoble: Editions Jérôme Millon, 2000, p. 319-331.

. Aristotle's Rhetoric on Emotions. In Barnes, J.; Schoefield, M.; Sorabji, R. (ed.) Articles on Aristotle. 4. Psychology and aesthetics. London: Duckworth, 1979, p. 133-153.

GOLDEN, L. The clarification theory of katharsis. Hermes, 104 (Heft 4), p. 437452, 1976. 
. Comic pleasure. Hermes, 115 (Heft 2), p. 165-174, 1987.

HALLIWELL, S. The Poetics of Aristotle. London: Duckworth, 1987.

HEATH, M. Aristotelian comedy. Classical Quarterly, 39, p. 344-354, 1989.

JANKO, R. Aristotle on comedy. Towards a reconstruction of Poetics II. Berkeley: University of California Press, 1984.

. Aristotle on comedy, Aristophanes and some new evidence from

Herculaneum. In Andersen, O; Haarberg, J. (ed.) Making sense of Aristotle. Essays in Poetics. London: Duckworth, 2001, p. 51-71.

NEHAMAS, A. Pity and fear in the Rhetoric and the Poetics. In Furley, D. J.; Nehamas, A. (ed). Aristotle's Rhetoric. Philosophal essays. Princeton/New Jersey: Princeton University Press, 1994, p. 257-282.

POSSEBON, F. Batracomiomaquia. A batalha dos ratos e das rãs. Estudo e Tradução. São Paulo: Humanitas - FFLCH/USP, 2003.

SCRUTON, R. Laughter. In The Aristotelian Society, supplementary vol. LVI, p. 197-212, 1982.

SOMMERSTEIN, A. Parler du rire chez Aristophane. In Desclos, M-L. (org.). Le rire des Grecs. Anthropologie du rire en Grèce ancienne. Grenoble: Editions Jérôme Millon, 2000, p. 65-75.

DUARTE, Adriane da Silva. Comic catharsis.

ABSTRACT: This paper intends to discuss the comic catharsis and identify which emotions play a role in this process, considering the aristotelic definition of passions (Rhetoric, II).

KEYWORDS: catharsis; Aristotle; Poetic; Rhetoric; old comedy. 